\title{
The Research of the Project Proprietor's Management Control of Engineering Change
}

\author{
Yanhua Pan, Yanfan Chen \\ Economic Management Institute of Jiangsu Science and Technology University, Zhenjiang, \\ Jiangsu, China
}

\begin{abstract}
The problem of the engineering budgetary estimate surpass engineering cost estimate, engineering budget surpass engineering budgetary estimate, engineering final accounts surpass engineering budget in our country's present stage of the engineering construction process is widespread, and the reason most due to engineering change. By reference to relevant case analysis, the study found the changing factors that induced engineering change largely are the proprietors' poor management of engineering change. Due to the different management methods of the different project stakeholders, this article will take the proprietors' point of view, relying on engineering change process, according to the characteristics of the construction project, reference to the project management concept, sums up the proprietor's management processes and methods. Then they can make manage and control in organize engineering change process and appraisal, then improve their management capacity of engineering change.
\end{abstract}

Keywords. proprietor; engineering change; project management

\section{Instruction}

In the process of project construction on present, the construction project change management has always been an important content. Due to engineering change changes the structure, standard, function, shape, material, equipment, etc., that not only affect the project progress objectives and investment objectives, accordingly leading to the final settlement price is much higher than the contract price, and also cause more uncertainty and additional risk, which make the engineering change repeatedly, the cost of handle change also became "bottomless pit". As early as in 1993, by research of Canada's 24 controversial claims in construction projects, Semple concluded that the engineering change is the main factors of the project investment, schedule overruns goal ${ }^{[1]}$. From 1997 to 2002, by study of the urban infrastructure projects, the regional urban construction auditor office concluded that the price of engineering change is between $10 \% \sim 25 \%$ of the contract price $^{[2]}$. Engineering change is, therefore, the main source of the engineering settlement price surpass contract price. The study of effectively control engineering change is significance.

Because of stakeholders has different ways of management and profit, the proprietors' as the sponsors and investors, have effects on project returns by managing the whole process of construction project. Chinese scholar $\mathrm{Wu}$ Shu'an based on the content of the engineering change made a classification of causes, and puts forward the difference classification control method of 
engineering change between different content ${ }^{[3]}$. Proprietor must to think about how to implement effective management to engineering change, and acknowledge the procedures and principles of control which plays a vital role on controlling the project progress, quality and investment.

Given all this, the domestic scholars held a positive attitude to the importance of the research on engineering change, and released a lot of research results, but made less research on the management approach measures, what proprietor effectively control the engineering change. So this paper, based on engineering change process, carding proprietor management process, according to the characteristics of the construction project, reference project management concept, sums up the proprietors' management processes and methods. Then they can make manage and control in organize engineering change process and appraisal, then improve their management capacity of engineering change.

\section{Construction projects engineering change management}

With the development of economy, management pattern is also changing. Construction project management takes the construction items as object. In the established constraint condition, according to its inherent law, make a planning, organization, coordination and control from the whole process of project conception to achieve the construction project, then to ensure that the construction project meet the required quality standards in allowing investment (or cost) ${ }^{[4]}$. Construction projects engineering change is a very complicated system, only follow the theory of project management can make it completed successfully. To implement the modernization management methods and means can achieve the ultimate goal. In this way, the role of proprietor in project management will gradually transition to the participants by the leader, who participate into the whole engineering change process of the project management, to ensure their own interests not be damage. Therefore, the author thinks that as a construction project proprietor during the engineering change must to do so as:

(1)Proprietors' responsibility of project management changes is during the whole project lifecycle stage and engineering change process.

(2) To ensure to realize the goal of engineering change, it should include risk assessment, cost, document, process, and evaluation management.

(3)Proprietors must to acknowledge with the government management content, to ensure the construction project conform to states laws.

\section{Process analysis of engineering change}

Some scholars put forward that the process of basic construction project is divided into six stages, namely, project proposal, feasibility study, design, construction preparation, implementation and completion acceptance stage ${ }^{[5]}$.This theory has been widely applied in the current construction project management. So in the literature, the proprietor must also make a program planning, organization and coordination, contract management, information management, risk management, and the three objectives control of schedule, investment, quality in the process of investment decision-making, design, planning, construction preparation, construction, completion acceptance, summarizes and evaluation ${ }^{[6]}$. On the basis of the above theory, refer to a changes flow which made by a construction company in Zhenjiang, the author constructed a typical flow charts of construction projects engineering change.

From figure 1 we can conclude that, the proprietor is the core of the construction projects engineering change. In order to reach the goal of the project management, the proprietor need to review and confirm the engineering change, and then give a strict control, tracking and verification in the process of change, which to ensure that the change was implemented correctly. Therefore, the author thinks that the proprietors' engineering change management should stick to the engineering change process, to carry out management work. 


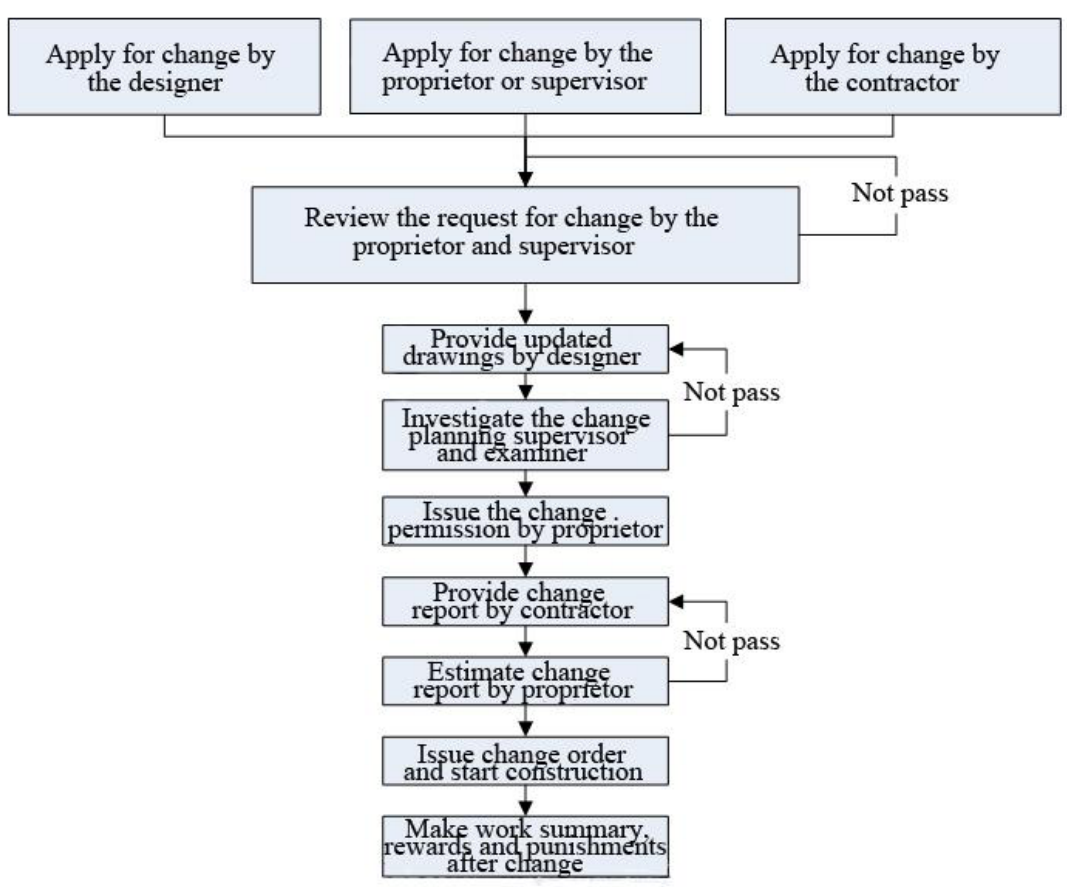

Figure 1. Process of construction projects engineering change

\section{Process management of construction project engineering}

According to the analysis of engineering change process, the author thinks that the engineering change management can be divided into four phases: (1) Preliminary examination of engineering change application by the proprietor; (2) Auditing of engineering change by the proprietor; (3) Supervision on engineering change construction; (4) Rewards and punishment on the management performance of engineering change by the proprietor.

\subsection{Preliminary examination of engineering change application}

According to the source of the changes, the process can be divided into: engineering change put forward by the proprietor, supervision, designer, and contractor. Reference a large number of cases and the literature, the author make a conclusion on the cause and the steps of engineering change proposed by different stakeholders, following as:

(1) Due to insufficient feasibility analysis on construction project work, when proprietor made a deviation and error on the selection of engineering plan, policy formulation, then they proposed changes application to the supervision according to the actual requirement, and Supervision Company entrusts the contractor according their purpose to fill change reason, quantities and cost, etc. If necessary, design units submit correspondingly the preliminary drawings of changes.

(2) When supervisions found the problems existing in the construction process or changes can optimized the whole or partial function on construction project, then they report to the proprietors to apply for engineering change, according to the actual requirement. And entrust a contractor according to their intended to fill change reason, related drawings and cost, etc.

(3) Due to the limitations of the design phase, the designer have short of understand on construction conditions, and hard to estimate the problems faced in construction phase, result in that make correct must on the basis of the actual construction conditions during actual construction. 
According to the actual need to report engineering change application and fill in change reason, relevant drawings and quantities, etc.

(4) Engineering change put forward by the contractors mainly concentrate on project construction phase. Due to the contractor master first-hand information of the construction project, in view of the indexes such as project progress, quality, cost, they propose positive opinions such as cost savings, improve the quality or negative opinions such as excess profit. They report the engineering change application, fill in engineering change reason, the related drawings, change of project quantities and amount.

Proprietor receipt the application for engineering change, and conduct a preliminary examination with the supervision and government departments, review the feasibility and necessity of the project change, mainly include: A. if the change of plan violate any of the relevant rules and regulations; $\mathrm{B}$. the feasibility of the change of plan drawings; $\mathrm{C}$. the rationality of change plan. The proprietor can carry out the evaluation work of the project change of plan after passes. If not passed, then refund of engineering change application report, canceled project changes.

\subsection{Auditing of engineering change by the proprietor}

This stage is the core steps of the proprietors review all engineering change project. Proprietors usually entrust a qualified cost office for help to review the cost of engineering change project, and more to assess risk on engineering change project, to weigh feasibility and necessity of engineering change application.

\subsubsection{Risk identification}

To identify the risk faced with construction projects is the foundation of the construction project risk management. Proprietor in identifying engineering change plan must to answer the following question: what are potential risk factors in the change project? What risk will be caused by these risk factors? Literature has summarized the current effective identification method: (1) Delphi method; (2) Brainstorming; (3) Decomposition analysis; (4) Check table; (5) Flow chart; (6) The accident tree method, etc. About the theory and method of project risk prediction and recognition, is still far from perfect, still need further research ${ }^{[7]}$.

It currently widely applied is flow diagram, check lists, financial statements and the accident tree analysis. The enterprise or the owner shall be to choose suitable methods for identification according to their own conditions. The author study to A construction project of Zhenjiang, then design diagram of change factors in the below.

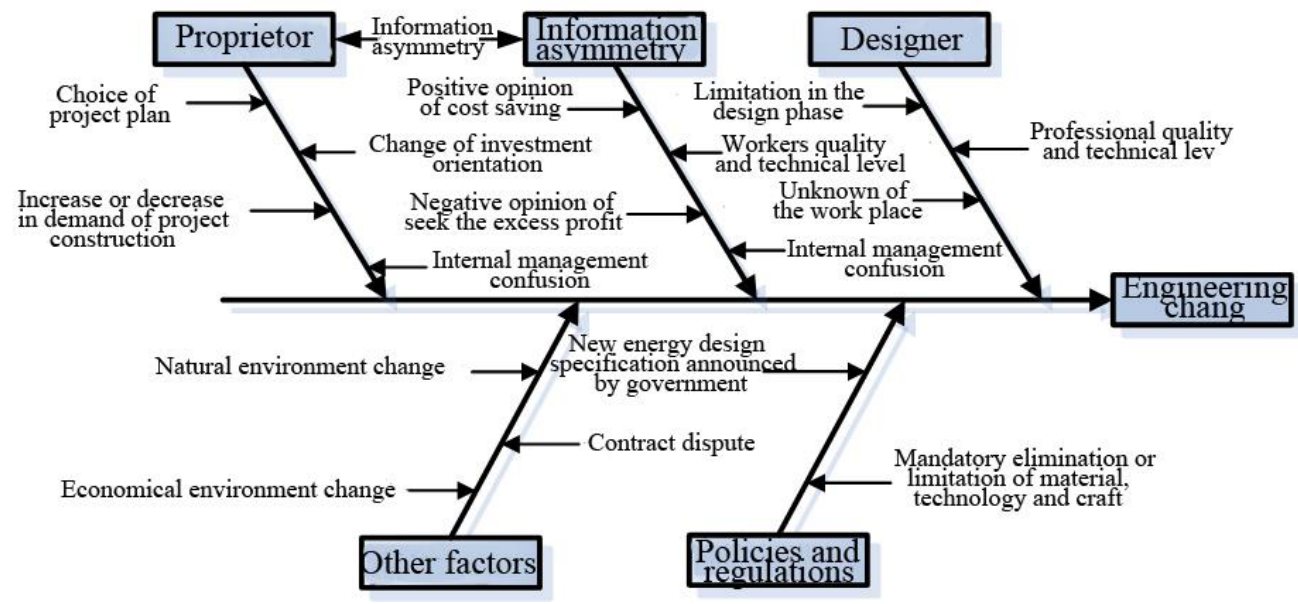

Figure 2. Factors of construction project engineering change 


\subsubsection{Risk analysis assessment}

Engineering change project risk assessment is the core of the assessment of engineering change application by proprietor, also is the premise of making the right decision. According to proprietors' own conditions to select the correct evaluation method is very important. Currently, Risk analysis evaluation methods include quantitative analysis (including sensitivity analysis, probability analysis, decision tree analysis, influence diagram technology, fuzzy mathematics method, and the CIM model, etc. $)^{[8]}$ and qualitative analysis (including curtain scene analysis, expert investigation, analytic hierarchy process, etc.). We should handle the relationship between the qualitative and quantitative analysis in risk assessment. However, in the process of engineering change project risk assessment, proprietor is limited to scarcity of data and the urgency of time, that lead them to face the embarrassing situation of lack of basic data, function value is not easy to solve during applying complex probability calculation and using the high- precision model. Therefore, the author thinks that in the process of engineering change risk assessment, the proprietor should combine quantitative analysis and qualitative, to reduce calculation difficulty, improve the computational efficiency.

\subsection{Supervision on engineering change construction}

Heste studied the influence on the operational productivity by the processing procedure of engineering change construction. The results showed that: Because of not keep full records of the construction site, it is difficult to calculate the influence of engineering change, then triggering some engineering claim and dispute ${ }^{[9]}$. Strengthen supervision by the proprietor on the engineering change can reduce the settlement of disputes and preventing safety accident, then effectively reduce the engineering change project payment, and shorten the construction period.

(1)Supervision on engineering change construction by proprietor

Due to the credit mechanism is imperfect in current construction market, the contractor of construction leading advantage in the market of labor, materials, construction machinery and other production factors. Only contractors know the consumption level of process and materials, so they may be give false change cost instead of reasonable change cost, to seek maximal benefits, then damage proprietor's interests. So proprietor must strengthen the supervision, to deal with change visa, price confirmed and claim etc., to avoid unnecessary disputes, litigation.

(2) Proprietor supervise the result feedback by supervision

Supervision within the scope authorized by proprietors supervise engineering change project construction and feedback in writing to the proprietors, who review the results feedback by supervisors, prevent supervision colluded with contractors to provide false reports, blinded them, causes their interests damaged.

\subsection{Rewards and punishment on the management performance of engineering change project}

Literature showed that proprietors lack of strict and scientific appraisal on performance of engineering change management. Because it doesn't set perfect construction engineering change control index system and the corresponding responsibility system and the incentive mechanism, it lead to project management personnel are neither pressure of managing engineering change, no power control engineering change, so out of control of engineering change management. It easy to give the poor professional ethics of project management personnel and the low credibility contractor chance to do bad things. The investment out of control in our country construction project for a long time. Also the crux of the "three surpass" phenomenon occurred frequently. Proprietors shall according to their own management organizational structure and project environment factors, select one or multiple superimposed method to rewards and punish. The 
author thinks that to carry out the performance evaluation work should do the following three points:

(1) Increase the pertinence of performance appraisal. It confirms the performance appraisal subject, examine the individual performance of the project or group's, and combine them organically. Improve the consciousness of what project management personnel should not only to affirm personal achievements but also can't ignore the joint efforts of the team.

(2) Perfect the performance appraisal system. Tie the performance evaluation results to rewards and punishment organically. Such as combine project management personnel's salary to career development and performance appraisal results, so to enhance the consciousness, motivation, and enforcement of project management.

(3) To ensure the fairness of performance appraisal.

\section{Conclusion}

Taking engineering change managing by A construction company in Zhenjiang as the foundation, through the analysis of the project management method to categorize the management process of the engineering change by proprietor, puts forward the four stages of management: (1) Preliminary examination of engineering change application by the proprietor; (2) Auditing of engineering change by the proprietor; (3) Supervision on engineering change construction; (4)Rewards and punishment on the management performance of engineering change project by the proprietor. Optimized the process of tissue engineering change, review of engineering change to meet the demand of the engineering change management and control. Those improved the proprietors' management ability of engineering change project. Project management method had to improve because of construction projects increasingly complicated. Hope that this analysis provides effective help to most proprietors, to strengthen their management ability of engineering change.

\section{References}

1. Clark .W.G. Claim avoidance and resolution [J]. American as association cost Engineering, Boston, and Mass, 1993.

2. Zhong Jilan, Theory of engineering change management and control $[\mathrm{J}]$. Construction Engineering, 2010(6): 41-42.

3. Wu Shu'an, Study of engineering change [D]. Master's thesis of Southeast University, 2006.

4. Shi Zhenwu, Construction project management [M], science press, 2014.5

5. Dai Qian, The proprietor's project management in project implementation phase $[\mathrm{J}]$. Hunan water resources and hydropower, 2005(3): 97-98.

6. Guo Handing, management guide on proprietor's construction project [M]. China machine press, 2006, 18.

7. Wang Lei, Study for major engineering change scheme based on value engineering [J]. 2012.

8. Huang Kailin, Zhao Hongxiang, Ji Taotao. Whole management process of engineering change [J]. Friends of Accounting, 2013(18): 40-43.

9. Fang Jun, research on construction project engineering change control [D]. Chongqing University, doctor's thesis, 2005. 